\title{
Effect of chitosan and cationic starch on the surface chemistry properties of bagasse paper
}

\author{
Alireza Ashori ${ }^{\mathrm{a}, *}$, Nereida Cordeiro $^{\mathrm{b}}$, Marisa Faria $^{\mathrm{b}}$, Yahya Hamzeh $^{\mathrm{c}}$ \\ a Department of Chemical Technologies, Iranian Research Organization for Science and Technology (IROST), P.O. Box 15815-3538, Tehran, Iran \\ ${ }^{\mathrm{b}}$ Competence Center in Exact Science and Engineering, University of Madeira, Funchal, Portugal \\ ${ }^{c}$ Department of Wood and Paper Science and Technology, Faculty of Natural Resources, University of Tehran, Karaj, Iran
}

\section{A R T I C L E I N F O}

\section{Article history:}

Received 19 February 2013

Received in revised form 2 April 2013

Accepted 17 April 2013

Available online 24 April 2013

\section{Keywords:}

Chitosan

Cationic starch

Hot water pre-extraction

Inverse gas chromatography

Surface chemistry

\begin{abstract}
A B S T R A C T
The use of non-wood fibers in the paper industry has been an economical and environmental necessity. The application of dry-strength agents has been a successful method to enhance the strength properties of paper. The experimental results evidencing the potential of chitosan and cationic starch utilization in bagasse paper subjected to hot water pre-extraction has been presented in this paper. The research analyzes the surface properties alterations due to these dry-strength agents. Inverse gas chromatography was used to evaluate the properties of surface chemistry of the papers namely the surface energy, active sites, surface area as well as the acidic/basic character. The results of the study revealed that the handsheets process causes surface arrangement and orientation of chemical groups, which induce a more hydrophobic and basic surface. The acid-base surface characteristics after the addition of dry-strength agents were the same as the bagasse handsheets with and without hot water pre-extraction. The results showed that the dry-strength agent acts as a protecting film or glaze on the surfaces of bagasse paper handsheets.
\end{abstract}

(c) 2013 Elsevier B.V. All rights reserved.

\section{Introduction}

Continuous improvement in the variety and quality of paper grades is essential for the success of the pulp and paper industry. New demands due to economic and especially environmental reasons have changed papermaking dramatically, forcing papermakers to improve the quality and increase the added-value of their products $[1,2]$. The use of non-wood fibers or recycled fibers in the paper industry has been an economical and environmental necessity over the last two decades. However, papermakers usually need the application of specific substances to enhance the end-use performance of their products [3].

The importance of mechanical properties, regarding the enduses of paper products, paper strength improvement has been a prime important consideration for papermakers when paper and paperboard products are not made exclusively from virgin wood fibers [4]. The application of dry-strength additive has been a successful method to enhance the strength properties of paper [5]. The wood fibers contain their own natural dry-strength additive in the form of hemicelluloses. The small amount of hemicelluloses removal from pulps makes it more difficult to develop their

\footnotetext{
* Corresponding author. Tel.: +98 215627 6637; fax: +98 2156276265

E-mail address: ashori@irost.org (A. Ashori).
}

bonding characteristics. Various dry-strength agents have been used throughout the years but a tendency towards the application of bio-chemicals is observed. The bio-chemicals, obtained from renewable resources, are based on organic macromolecules of biological origin represented mainly by polysaccharides, such as starch and Chitosan [6]. These highly hydrophilic polymers have chemical structures similar to cellulose, enabling them to participate in extensive hydrogen bonding with fiber surfaces. Since the surface of fibers is negatively charged, the application of products with cationic groups attached to the main chain increases the attraction between the molecules of dry-strength agents and fibers. Because of this, unmodified starch has little affinity to cellulosic fibers; therefore, almost all starches strengths are cationic. Cationic starch gives better natural retention due to its positive charge, which makes it adhere to negatively charged fibers under normal papermaking conditions. Starch derivatives represent the most common and by far the largest amount of dry-strength agents [7].

Due to its biodegradability, biocompatibility, antimicrobial activity, nontoxicity, and versatile chemical and physical properties, chitosan has a great potential for a wide range of applications [8]. Chitosan is the main derivative of chitin, which is the second polysaccharide on earth, after cellulose. The unique structural feature of chitosan is the presence of primary amines at the C-2 position of the $\mathrm{D}$-glucosamine residues. These amine groups, in the first place, allow specific chemical reactions, and secondly confer 
important functional properties to chitosan, which can be exploited for application in a variety of areas, included in the paper industry as a dry-strength additive, due to its abundance and comparative cost-effectiveness [9,10].

Chemical modification of the paper by dry-strength agent, changes the structural and chemical properties, including the surface energy of the paper and its hydrophilic/hydrophobic surface character. In the particular case of the printing paper, the surface characterization is one of the most important factors concerning consumers' evaluation. Thus, all the studies dealing with printing quality, paper surface properties and paper-ink interaction are of utmost importance. Inverse gas chromatography (iGC) is a very useful method to determine the surface properties of a solid. Unlike gas chromatography, this analytical chromatography method is used as stationary phase for samples whose properties are unknown, and as mobile phase for probe molecules with known properties. Through the passage of these probes, it is possible to determine the characteristics of the solid surface by the their retention times. The dispersive and specific components of the surface free energy, acid-base character, adsorption isotherm, monolayer capacity, surface area and heterogeneity are some of the properties obtained through $i$ GC analysis.

\subsection{Dispersive component of the surface energy}

The dispersive component of the surface energy $\left(\gamma_{S}^{D}\right)$ is determined using dispersive probes molecules namely homologous $n$-alkanes through the pulse technique. The retention time obtained from the interaction between the probes molecules and the solid surface allows us to determine the dispersive surface free energy, $\Delta G_{a d s}$, obtained by Eq. (1) [11]:

$\Delta G_{a d s}=R T \ln V_{N}=2 N_{A}\left(\gamma_{S}^{d}\right)^{1 / 2} a\left(\gamma_{L}^{d}\right)^{1 / 2}+K$

where $R$ is the gas constant, $K$ is a constant depending on the chosen reference state, $T$ is the column temperature, $V_{N}$ is the net retention volume, $\gamma_{S}^{d}$ denotes the dispersive component of surface free energy of the solid, $\gamma_{L}^{d}$ denotes the dispersive component of the surface free energy of the test solute, $a$ is the area occupied by probe molecule and $N$ is the Avogadro's number. Component $\gamma_{S}^{d}$ can be calculated from the slope of the obtained line in the plot of $\Delta G_{a d s}$ versus $a\left(\gamma_{L}^{d}\right)^{1 / 2}$ of the series of $n$-alkanes.

\subsection{Specific component of the surface energy (acid-base properties)}

Specific component of the surface energy, $\Delta G_{a d s}^{s p}$, is one parameter of the surface energy giving the contribution of Lewis acid-base interactions with the solid surface through polar probes. The polar molecules and solid interactions involve two terms: dispersive, $\Delta G_{a d s}^{d}$, and specific, $\Delta G_{a d s}^{s p}$, interactions. $\Delta G_{a d s}$ is determined by the Eq. (2).

$\Delta G_{a d s}=\Delta G_{a d s}^{d}+\Delta G_{a d s}^{s p}$

$\Delta G_{a d s}^{s p}$ can be determined using Fowkes plot with the following relation [12]:

$\Delta G_{a d s}^{s p}=R T \quad \ln V_{N}-R T \quad \ln V_{N(r e f)}$

where $V_{N}$ is the net retention volume for the polar probe and $V_{N(r e f)}$ is the net retention volume established by the $n$-alkane reference line for the same polar probe. Through specific enthalpy of adsorption, it is possible to quantify the Lewis acidity and Lewis basicity of the non-volatile material using with the following equation $[13,14]$ :

$\frac{\Delta H_{a d s}^{s p}}{A N *}=\frac{D N}{A N^{*}} \times K_{A}+K_{B}$

where $A N^{*}$ and $D N$ are Guttmann's modified acceptor and donor numbers, respectively; $K_{A}$ is a Lewis acidity constant and $K_{B}$ is a Lewis basicity constant.

\subsection{Isotherm measurements}

Using a wide variety of probe molecules at different temperatures, adsorption isotherm is obtained by applying BET equation as follows [15]:

$\frac{p}{n\left(p_{\circ}-p\right)}=\frac{1}{n_{m} c}+\frac{c-1}{n_{m} c} \times \frac{p}{p_{\circ}}$

where $n_{m}$ is a monolayer capacity, $n$ is the amount adsorbed, $p$ is the partial pressure, $p$ is the saturation pressure and $c$ is related to the heat of sorption. Knowing the monolayer capacity and the cross area, $a_{m}$, of a probe molecule, the surface area can be calculated by Eq. (6).

$S_{B E T}=a_{m} n_{m} N_{A}$

where $N_{A}$ is the Avogadro constant.

Through the adsorption isotherm, the heterogeneity of the surface can be deduced from the adsorption potential, $A$, by the following equation [16]:

$A=R T \ln \left(\frac{p_{\circ}}{p}\right)$

In this paper, the effects of addition of dry-strength agents, namely chitosan and cationic starch, on the surface properties were investigated.

\section{Materials and methods}

\subsection{Materials}

Bagasse stalks, obtained from the Khuzestan and Industry Co., Iran, were subjected to hot water pre-extraction as described by Cordeiro et al. [17].

Two dry-strength agents were used in this study: chitosan and cationic starch. High-molecular weight chitosan was a Sigma-Aldrich product (USA), a material with $85.4 \%$ desacetylation and molecular weight of $9 \times 10^{5} \mathrm{~g} / \mathrm{mol}$. The cationic starch used in this study was made from potato and was obtained from Lyckeby Amylex Co. It contained about $17 \%$ amylase and $83 \%$ amylopectin and had a degree of substitution of 0.065 .

The non-polar and polar molecules used for the iGC measurements were all GC grade (>99\% purity) supplied by Sigma-Aldrich. The methane gas (reference probe) and helium (carrier gas), of high purity (>99.99\%), were supplied by Air Liquide Company. All the solutions used in this work were freshly prepared to avoid any possible degradation.

\subsection{Pulp process}

Pulps from raw and hot water pre-extracted bagasse fibers were obtained using the following pulping conditions: initial solid:liquid ratio of $1: 5$, temperature of $433 \mathrm{~K}$ and pulping time of $60 \mathrm{~min}$. The amount of active alkali was $14 \%$. After cooking, the pulps were thoroughly washed with fresh water on a fine filter, and then disintegrated in a hydropulper at 30,000 revolutions and $0.5 \%$ consistency for $5 \mathrm{~min}$. Pulps from pre-extracted and un-extracted 


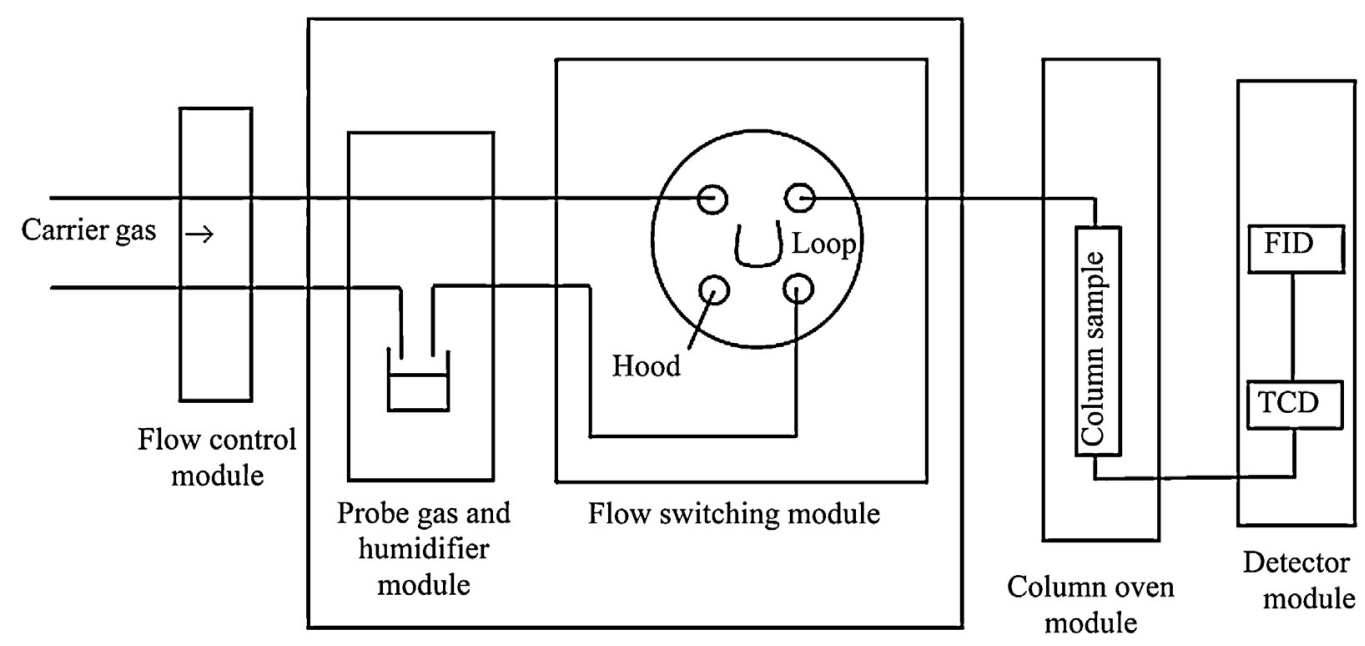

Fig. 1. Schematic diagram of used $i$ GC set-up for pulse analysis with headspace injection.

bagasse were bleached by conventional elemental chlorine free (ECF) bleaching sequences [17].

\subsection{Application of dry-strength agents}

The chitosan solution was prepared by dissolving in $1 \%$ acetic acid at room temperature by stirring for $8 \mathrm{~h}$, whereas the cationic starch was prepared by suspending starch powder in distilled water and heating to $368 \mathrm{~K}$ in a water bath with periodic stirring and then holding the suspension at this temperature for $30 \mathrm{~min}$ after the onset of gelatinization. The solutions were then diluted with distilled water prior to use. Chitosan was applied in dosages of $0.25,0.5$ and $1.0 \%$, while cationic starch was used in dosages of 0.5 and $1.5 \%$ based on oven-dry weight of pulp. The different polymers dosage solutions were added to a $1 \%$ suspension of bleached pulp. The mixture was agitated for $30 \mathrm{~min}$ at room temperature $(298 \mathrm{~K})$. The suspension was then diluted with distilled water to $0.5 \%$.

\subsection{Sheet formation and paper handsheets testing}

After mixing the pulp suspension for $20 \mathrm{~min}$, handsheets $\left(60 \mathrm{~g} / \mathrm{m}^{2}\right)$ were made in a British handsheet former as per TAPPI Standard T 205 sp-02. The samples were conditioned at $50 \pm 2 \%$ relative humidity and $296 \pm 1 \mathrm{~K}$ temperature according to TAPPI $\mathrm{T}$ $402 \mathrm{sp}-98$ for at least $4 \mathrm{~h}$. The handsheets were tested for tensile index (T 494 om-01) and burst index (T 403 om-97).

\subsection{Inverse gas chromatograph analysis}

The iGC measurements were carried out on a commercial inverse gas chromatography (Surface Measurements Systems, London, UK), equipped with a flame ionization detector (FID) and a thermal conductivity detector (TCD). The system is fully automatic with SMS iGC Controller V 1.8 Control Software. The columns used were standard glass silanized (dymethyldichlorosilane; Repelcote $\mathrm{BDH}, \mathrm{UK}$ ) with $300 \mathrm{~mm}$ length and an internal diameter of $3 \mathrm{~mm}$. The bagasse paper handsheets were packed in the columns by vertical tapping for $2 \mathrm{~h}$ using the SMS sample packing device. The columns were placed in the iGC column oven module (Fig. 1) and conditioned over night at $313 \mathrm{~K}$ with helium flow rate of $10 \mathrm{ml} / \mathrm{min}$, in order to remove the impurities adsorbed on the surface. After conditioning, pulse injections were carried out with a $250 \mu \mathrm{L}$ gas loop. Fig. 2 shows the used $i$ GC setup for pulse injections with a headspace injection system. Briefly, the carrier gas (Helium) is passed through a reservoir, containing the probe molecule in its liquid form, where the carrier gas is saturated with the probe molecule and then flows through the injection loop. The concentration and the amount of probe molecule are controlled via the temperature and the loop volume. After the probe molecule injection, the adsorption followed by desorption takes place in the column sample situated in a separate column oven module. The interaction probe/sample causes retention, similar to analytical chromatography. In this study, the retention time was calculated from the FID response. Fig. 2 shows a typical response of FID to the $n$-alkanes probes and for the methane (tracer molecule which was used to calculate the dead time). The retention volume and subsequent data were analyzed using iGC Standard v1.3 and iGC Advanced Analysis Software v1.25 based on the equations explained in the previous section. The physical constants for probes used in iGC calculations were taken from the literature and are presented in Table 1.

The dispersive component of the surface free energy was determined by applying four $n$-alkanes: $n$-heptane, $n$-octane, $n$-nonane and $n$-decane at $298 \mathrm{~K}$. Acetonitrile, ethyl acetate, ethanol and tetrahydrofuran were the polar molecules used for the determination of the Gibbs specific free energy and acid-base surface character at the same temperature and conditions as the previous experiments. The $n$-octane was the probe molecule used to determine the parameters of isotherm and permeability experiments at $298 \mathrm{~K}$. All the measurements were carried out at $0 \%$ relative humidity (RH), a helium flow rate of $10 \mathrm{~mL} / \mathrm{min}$ and in duplicate, producing an experimental error less than $3 \%$.



Fig. 2. Typical response of FID to the $n$-alkanes probes $\left(C_{6}-C_{8}\right)$ and for methane. 
Table 1

Physical constants of the probes used in iGC experiments.

\begin{tabular}{|c|c|c|c|c|c|}
\hline Probe & $a\left(10^{-19} \mathrm{~m}^{2}\right)$ & $\gamma_{L}^{d}\left(\mathrm{~mJ} / \mathrm{m}^{2}\right)$ & $D N(\mathrm{kcal} / \mathrm{mol})$ & $A N^{*}(\mathrm{kcal} / \mathrm{mol})$ & $D N / A N^{*}$ \\
\hline n-Hexane & 5.15 & 18.4 & - & - & - \\
\hline n-Heptane & 5.73 & 20.3 & - & - & - \\
\hline$n$-Octane & 6.30 & 21.3 & - & - & - \\
\hline$n$-Nonane & 6.90 & 22.7 & - & - & - \\
\hline$n$-Decane & 7.50 & 23.4 & - & & - \\
\hline Ethanol & 3.53 & 21.1 & 19.0 & 10.3 & 1.84 \\
\hline Acetonitrile & 2.14 & 27.5 & 14.1 & 4.7 & 3.00 \\
\hline Acetone & 3.40 & 16.5 & 17.0 & 2.5 & 6.80 \\
\hline Ethyl Acetate & 3.30 & 19.6 & 17.1 & 1.5 & 11.4 \\
\hline Tetrahydrofuran & 2.90 & 22.5 & 20.0 & 0.5 & 40.0 \\
\hline
\end{tabular}

$a$ : Cross-sectional area; $\gamma_{L}^{d}$ : surface tension; $A N^{*}$ : electron acceptor number $\left[A N^{*}=0.288\left(A N-A N_{d}\right)\right]$; $D N$ : electron donor number.

Based on: [11,21]

\section{Results and discussion}

The bagasse paper handsheets were subjected to analysis by iGC, and the surface properties were exhaustively studied through the passage of probe molecule to verify how the addition of chitosan and cationic starch affected the surface properties of the paper handsheets. The use of $n$-alkanes, as non-polar hydrocarbon probe molecules, allows the determination of the dispersive component of surface energy $\left(\gamma_{S}^{d}\right)$ through the plot of $R T \ln V_{N}$ versus $a\left(\gamma_{L}^{d}\right)^{1 / 2}$ (Eq. (1)) for the bagasse paper handsheets, as shown as example in Fig. 3 for un-extracted and pre-extracted paper handsheets with and without dry-strength agents. Table 2 presents the values obtained for the bagasse paper at $298 \mathrm{~K}$. The $\gamma_{S}^{d}$ values obtained for the bagasse paper handsheets are close to those reported in literature for similar fibers/materials [18]. Cordeiro et al. [17]
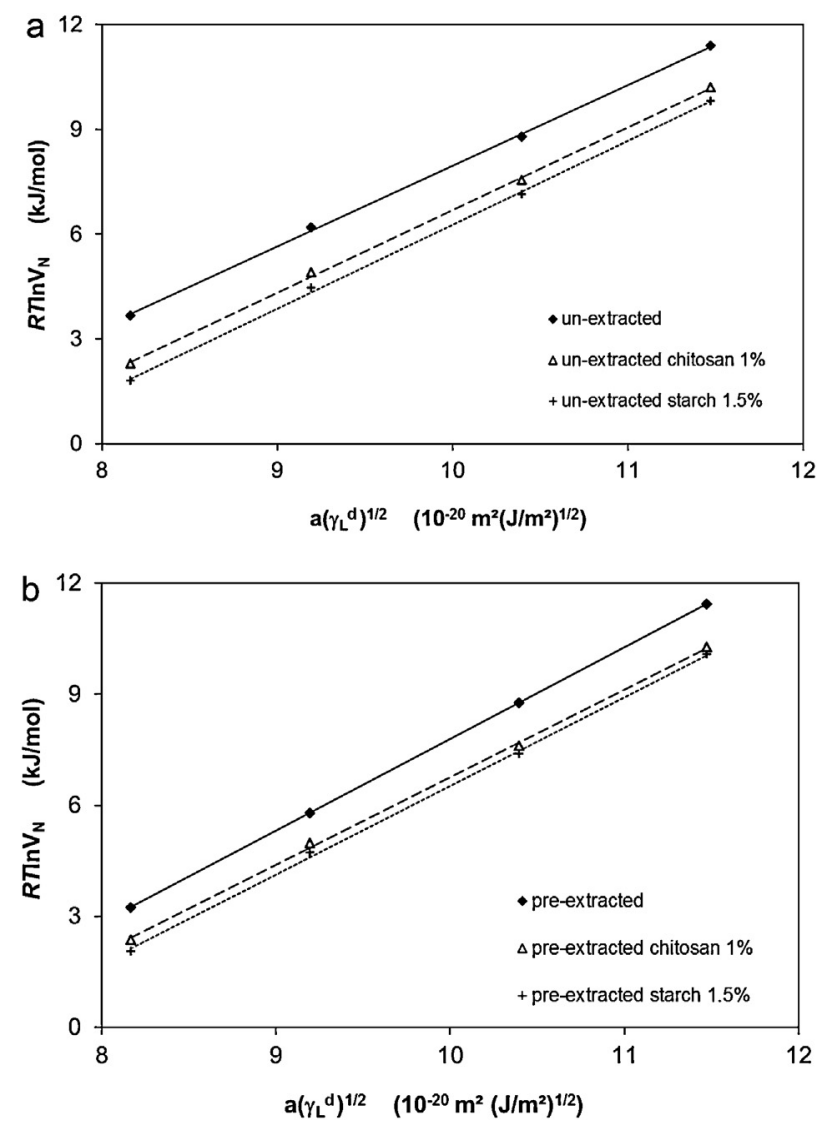

Fig. 3. Plot of $R T \ln V_{N}$ versus $a\left(\gamma_{L}^{d}\right)^{1 / 2}$ for the $n$-alkanes onto un-modified and modified with chitosan and cationic starch: (a) un-extracted and (b) pre-extracted fibers at $298 \mathrm{~K}$. found $\gamma_{S}^{d}$ value of $48 \mathrm{~mJ} / \mathrm{m}^{2}$ for the bagasse pulp fibers. Thus, the handsheets process causes the fibers surface arrangement and orientation of chemical groups, which considerably improves the fiber bonding and gives a stronger paper, changing the diffusion of probes molecules and variations in the $\gamma_{S}^{d}$.

According to the results (Table 2), the handsheets subjected to hot water pre-extraction present a higher $\gamma_{S}^{d}$ value. However, it is observed that the $\gamma_{S}^{d}$ increases for the un-extracted paper handsheets and decreases in the pre-extracted paper handsheets. The addition of dry-strength agents results in samples with similar surface energy. The results revealed that the dry-strength agents adhere to the paper fibers and form a film at the surface. Thus, the $\gamma_{S}^{d}$ differences in the paper handsheets, motivated by the hot water pre-extraction, were nullified by the dry-strength agent addition of chitosan and cationic starch.

Once the non-polar probe molecules interact only through dispersive interaction, the increase of $\gamma_{S}^{d}$ in un-extracted samples with chitosan and cationic starch indicates that the fiber has become more hydrophobic while the pre-extracted samples is less hydrophobic with addition of both dry-strength agents. This variation is due to the modifications in the number and energy of the active sites, as shown by the energetic profile of the surface heterogeneity (Fig. 4) determined by BET model [16], through the injection of different concentration of $n$-octane at $298 \mathrm{~K}$. The symmetrical peaks and the linear adsorption isotherm described by Henry's Law were obtained. The $A_{\max }$ values obtained were between 4.97 and $5.69 \mathrm{~kJ} / \mathrm{mol}$. A number of studies have reported that the $A_{\max }$ values for different natural fibers are between 8.40 and $14.15 \mathrm{~kJ} / \mathrm{mol}$ $[19,20]$. The smaller values found for the bagasse paper handsheets can be due to the presence of chitosan and cationic starch at the surface of the handsheets paper, which makes the surface non-polar actives sites less energetic.

Compared to morphologic aspects, namely particle size and surface area $\left(S_{B E T}\right)$, the $S_{B E T}$ results (Table 3 ) show a decrease after a small addition of dry-strength agent, increasing with higher concentrations. This is indicative of an incomplete crosslink (particle size increase) with the small dry-strength agent amount and a bigger reticulation with the increase in the amount of dry-strength agents (particle size decrease). This supposition was backed by the progressive tendency, observed in the $\gamma_{S}^{d}$ and $K_{\mathrm{b}} / K_{\mathrm{a}}$ values. The diffusion coefficient $\left(D_{p}\right)$ data also supports this conclusion. A significant decrease in the $D_{p}$ value was an indicative of the particles compaction, in this case the chain crosslink process, which provokes larger reduction of the probe diffusion in the bagasse paper handsheets.

In the framework of studying the influence of dry-strength agents on acid-base character of the fiber surface, four polar probe molecules (tetrahydrofuran, ethanol, acetonitrile and ethyl acetate) were injected and the specific component of surface energy was determined at $298 \mathrm{~K}$ and calculated according to Eq. (3). For all 
Table 2

Dispersive component of the surface, $\gamma_{S}^{d}$, and acid/base constants obtained for bagasse paper handsheets at $298 \mathrm{~K}$.

\begin{tabular}{|c|c|c|c|c|c|}
\hline Samples & $\gamma_{S}^{d}\left(\mathrm{~mJ} / \mathrm{m}^{2}\right)$ & $K_{\mathrm{a}}$ & $K_{\mathrm{b}}$ & $K_{\mathrm{b}} / K_{\mathrm{a}}$ & \\
\hline \multirow{5}{*}{ Un-extracted paper } & Un-treated & 36.95 & 0.09 & 0.11 & 1.22 \\
\hline & Chitosan $0.25 \%$ & 40.06 & 0.09 & 0.10 & 1.11 \\
\hline & Chitosan $1.0 \%$ & 38.72 & 0.09 & 0.09 & 1.00 \\
\hline & Cationic starch $0.5 \%$ & 38.46 & 0.09 & 0.08 & 0.89 \\
\hline & Cationic starch 1.5\% & 39.69 & 0.09 & 0.08 & 0.89 \\
\hline \multirow{5}{*}{ Pre-extracted paper } & Un-treated & 42.31 & 0.09 & 0.12 & 1.33 \\
\hline & Chitosan $0.25 \%$ & 40.51 & 0.09 & 0.10 & 1.11 \\
\hline & Chitosan $1.0 \%$ & 38.51 & 0.09 & 0.09 & 1.00 \\
\hline & Cationic starch $0.5 \%$ & 39.09 & 0.09 & 0.08 & 0.89 \\
\hline & Cationic starch $1.5 \%$ & 39.63 & 0.09 & 0.08 & 0.89 \\
\hline
\end{tabular}

$\gamma_{S}^{d}$ : dispersive component of surface energy $\left(\mathrm{mJ} / \mathrm{m}^{2}\right) ; K_{\mathrm{a}}$ : acidic constant; $K_{\mathrm{b}}$ : basic constant; excellent linear fit was obtained ( $\left.>0.99\right)$.

Table 3

Specific surface area, monolayer capacity and permeability degree for bagasse paper handsheets at $298 \mathrm{~K}$.

\begin{tabular}{|c|c|c|c|c|}
\hline Samples & $S_{B E T}\left(\mathrm{~m}^{2} / \mathrm{g}\right)$ & $n_{\mathrm{m}}(\mu \mathrm{mol} / \mathrm{g})$ & $D P\left(\mathrm{~cm}^{2} / \mathrm{sec}\right)$ & \\
\hline \multirow{5}{*}{ Un-extracted paper } & Un-treated & 1.20 & 3.48 & 0.219 \\
\hline & Chitosan $0.25 \%$ & 1.04 & 2.74 & 0.037 \\
\hline & Chitosan $1.0 \%$ & 1.21 & 3.18 & 0.034 \\
\hline & Cationic starch $0.5 \%$ & 1.15 & 3.03 & 0.027 \\
\hline & Cationic starch $1.5 \%$ & 1.24 & 2.49 & 0.024 \\
\hline \multirow{5}{*}{ Pre-extracted paper } & Un-treated & 1.40 & 4.74 & 0.352 \\
\hline & Chitosan $0.25 \%$ & 1.02 & 2.69 & 0.026 \\
\hline & Chitosan $1.0 \%$ & 1.23 & 3.23 & 0.022 \\
\hline & Cationic starch $0.5 \%$ & 1.06 & 2.80 & 0.030 \\
\hline & Cationic starch $1.5 \%$ & 1.23 & 3.23 & 0.024 \\
\hline
\end{tabular}

$\mathrm{S}_{\mathrm{BET}}$ : surface area $\left(\mathrm{m}^{2} / \mathrm{g}\right) ; \mathrm{n}_{\mathrm{m}}$ : monolayer capacity $(\mu \mathrm{Mol} / \mathrm{g}) ; \mathrm{D}_{\mathrm{p}}$ : Van Deemter constant $\left(\mathrm{cm}^{3} / \mathrm{sec}\right)$. Linear fit between 0.992 and 0.999 .
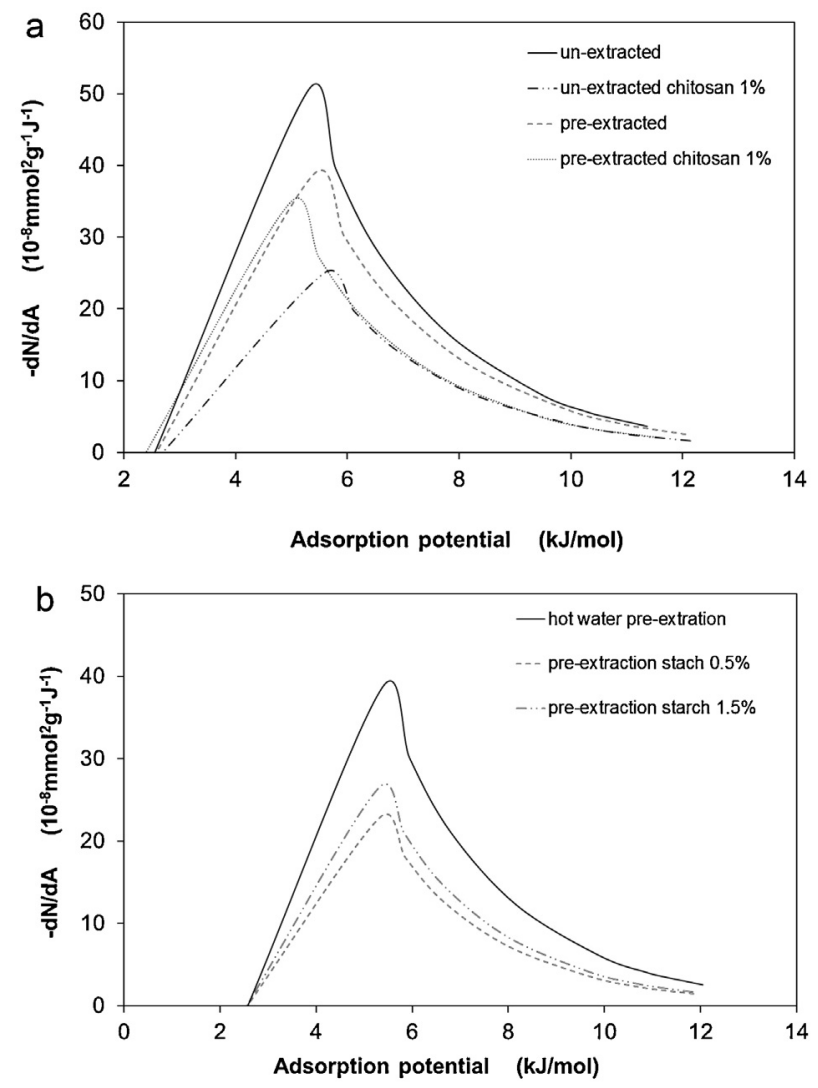

Fig. 4. Heterogeneity profiles obtained with n-octane for cellulose fibers unextracted and pre-extracted modified with (a) chitosan and (b) cationic starch at $298 \mathrm{~K}$. the bagasse paper handsheets, strong interactions with acetonitrile probe molecule were detected (Fig. 5), which indicates the presence of both acid and base groups in the surface of the paper handsheets. For all probes, a decrease in the $\Delta G_{S}^{s p}$ values was observed, that can be indicative of the decrease in polar active sites at the surface. This effect seems more significant to the basic sites with greater decrease in the ethanol probe (the acid probe) than in the tetrahydrofuran probe (the basic probe). The surface acid-base character was evaluated by the $K_{\mathrm{a}}$ and $K_{\mathrm{b}}$ values, calculated through $\Delta G_{S}^{s p}$ using Eq. (4), the Gutmann's concept [21]. The paper handsheets present a less basic surface compared to the bagasse pulp fibers [17]. As mentioned earlier, the handsheets process provokes the fibers surface arrangement and orientation of chemical groups, which induces variations in acid-basic properties of the surface. In spite of this, the predominant basic character was also found in the un-treated paper handsheets, with the pre-extracted paper

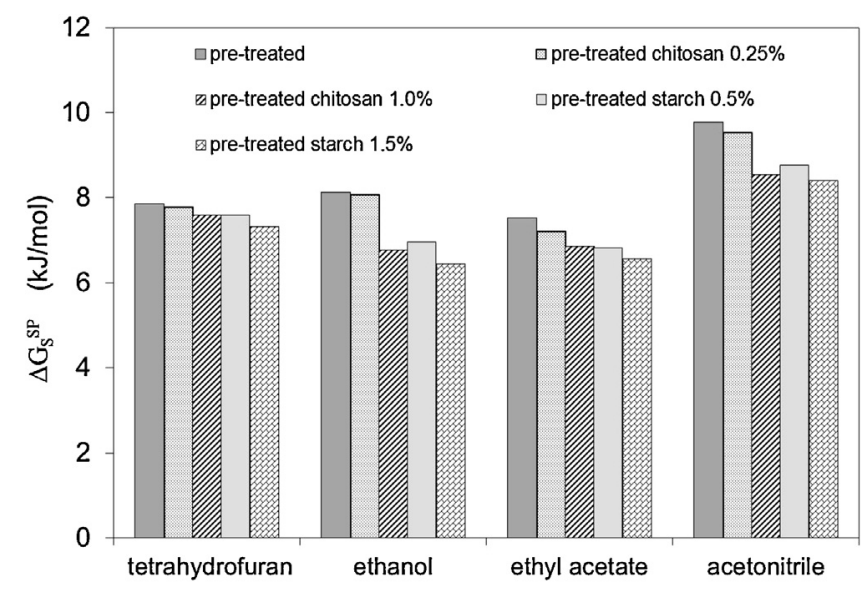

Fig. 5. Specific surface free energy, $\Delta G_{S}^{s p}$, obtained for pre-extracted fibers modified with chitosan and cationic starch at $298 \mathrm{~K}$. 
handsheets showing a higher ratio $K_{\mathrm{b}} / K_{\mathrm{a}}(1.33)$ than un-extracted paper handsheets with $K_{\mathrm{b}} / K_{\mathrm{a}}$ ratio of 1.22 (Table 2 ). For the paper handsheets made with dry-strength agents, the $K_{\mathrm{a}}$ (related to the hydroxyl groups at the surface) remains constant for all samples, independent of the added dry-strength agents and its concentration. However, changes in the bagasse paper handsheet acid-base character were observed with the addition of dry-strength agents, due to a decrease in the $K_{\mathrm{b}}$. In the case of chitosan, the addition to the paper handsheets surface came with a neutral character $\left(K_{\mathrm{b}} / K_{\mathrm{a}}\right.$ of 1.00$)$, but with the cationic starch the handsheets surface changed to a predominantly acid character with a ratio $K_{\mathrm{b}} / K_{\mathrm{a}}$ of 0.89 . The surface acid-base character is governed by the availability of functional groups at the paper surface. Thus, the decrease in the basic groups at the surface is due to the bonding between the cationic groups from dry-strength agents and the cellulosic basic groups.

As observed in the case of the surface energy, the acid-base surface characteristics after the addition of the dry-strength agents are the same as the bagasse handsheets with and without hot water pre-extraction. These observations enabled the confirmation of the solid hypotheses concerning the adhesion of the dry-strength agent to the pulp fibers with the formation of a film on the handsheets paper surface.

\section{Conclusions}

As expected, this study confirms that the addition of the dry-strength agents has a positive effect in the bagasse handsheets paper. Thus, the addition of chitosan and cationic starch could decrease the negative impact on the pulp properties of the hot water pre-extraction. The $i \mathrm{GC}$ revealed to be a powerful and reliable tool in this study, showing:

(1) That the handsheets process causes surface arrangement and orientation of chemical groups, which induces a more hydrophobic and basic surface;

(2) An effective crosslink between the dry-strength agents and the bagasse pulp fibers;

(3) That the dry-strength agent adheres to the pulp fibers and forms a film on the surface of the bagasse paper handsheets. This film was responsible for the similar surface properties of the paper handsheets obtained with or without hot water preextraction;

(4) Changes in the predominantly basic character in bagasse paper handsheets surface with the addition of dry-strength agents: paper handsheets surface came with a neutral character with the addition of chitosan, but with the cationic starch the surface has a predominant acid character;

(5) A significant decrease in the surface area due to the crosslink between the dry-strength agents and the bagasse pulp fibers.

Finally, it should be pointed out that the results show the feasibility of using chitosan and cationic starch as dry-strength for application of non-wood materials in the paper industry.

\section{Acknowledgements}

Portuguese authors would like to thank the "Programa Nacional de Re-equipamento Científico", POCI 2010, by sponsored iGC work (FEDER and Foundation for the Science and Technology).

\section{References}

[1] M.A. Hubbe, A. Sundberg, P. Mocchiutti, Y. Ni, R. Pelton, BioResources 7 (2012) 6109-6193.

[2] Y. Hamzeh, A. Ashori, Z. Khorasani, A. Abdulkhani, A. Abyaz, Industrial Crops and Products 43 (2013) 365-371.

[3] S.M. Costa, P.G. Mazzola, J.C.A.R. Silva, R. Pahl, A. Pessoa, S.A. Costa, Industrial Crops and Products 42 (2013) 189-194.

[4] A. Jun, U.W. Tschirner, Z. Tauer, Biomass and Bioenergy 37 (2012) 229-236.

[5] M. Moshkelani, M. Marinova, M. Perrier, J. Paris, Applied Thermal Engineering 50 (2013) 1427-1436

[6] Y. Hamid, A.A. Bakar, N. Deirram, Journal of Applied Polymer Science 128 (2013) 1170-1175.

[7] A. Ashori, W.D. Raverty, H. Jalaluddin, Iranian Polymer Journal 14 (2005) 807-814.

[8] J. Araki, Y. Yamanaka, K. Ohkawa, Polymer Journal 144 (2012) 713-717.

[9] A. Ashori, H. Jalaluddin, W.Y. Wan Md Zin, M.Y. Mohd Nor, Polymer - Plastics Technology and Engineering 45 (2006) 125-129.

[10] A.G. Cunha, A. Gandini, Cellulose 17 (2010) 1045-1065.

[11] J. Schultz, J. Lavielle, Interfacial properties of carbon fiber-epoxy matrix composites, ACS Symp. Series 391, Washington, 1989

[12] P.R. Rani, S. Ramanaiah, K.S. Reddy, Surface and Interface Analysis 43 (2011) 683-688.

[13] A. Voelkel, Critical Reviews in Analytical Chemistry 22 (1991) 411-439.

[14] D. Cava, R. Gavara, J.M. Lagarón, A. Voelkel, Journal of Chromatography A 1148 (2007) 86-91.

[15] S. Brunauer, P.H. Emmet, E. Teller, Journal of the American Chemical Society 60 (1938) 309-319.

[16] J. Condor, C. Young, Physicochemical measurement by gas chromatography, John Wiley and Sons, Chichester, UK, 1979.

[17] N. Cordeiro, A. Ashori, Y. Hamzeh, M. Faria, Materials Science and Engineering C 33 (2013) 613-617.

[18] N. Cordeiro, M. Ornelas, A. Ashori, S. Sheshmani, H. Norouzi, Carbohydrate Polymers 87 (2012) 2367-2375.

[19] N. Cordeiro, C. Gouveia, M. Jacob John, Industrial Crops and Products 33 (2011) $108-115$.

[20] N. Cordeiro, C. Gouveia, A.G.O. Moraes, S.C. Amico, Carbohydrate Polymers 84 (2011) 110-117.

[21] V. Gutmann, The Donor-Acceptor Approach to Molecular Interactions, Plenum Publ. Corp, New York, 1978. 